\title{
INFLUENCE OF MOISTURE ON THE FRACTURE BEHAVIOUR OF CONCRETE LOADED IN DYNAMIC TENSION
}

\author{
I. VEGT ${ }^{\dagger}$ AND J. WEERHEIJM ${ }^{\dagger *}$ \\ ${ }^{\dagger}$ Delft University of Technology \\ Delft, The Netherlands \\ e-mail: i.vegt@tudelft.nl \\ "TNO Defence, Safety and Security \\ Rijswijk, The Netherlands \\ e-mail: j.weerheijm@tudelft.nl
}

Key words: rate effects, concrete, tension, moisture, experiments, fracture characteristics

\begin{abstract}
Dynamic tests demonstrate an extensive rate effect on the tensile strength as well as the post-peak behaviour beyond loading rates of about $50 \mathrm{GPa} / \mathrm{s}$. One of the possible explanations for the observed rate effects on the fracture behaviour is enhanced resistance by moisture in the pores. To study the influence of the moisture content and pore structure on the rate dependency, different moisture contents and concrete types are used and tested at three loading rates.

From the test results it is concluded that the moisture volume, porosity and pore structure play an important role for tensile strength as well as the fracture process. The NMR tests showed that the water in the capillary pores causes the strength increase and not the water in the gel-pores.

From the analysis of the experimental results it is concluded that for loading rates $<50 \mathrm{GPa} / \mathrm{s}$, the main cause for the observed strength increase is the viscous behaviour of concrete. For loading rates beyond $50 \mathrm{GPa} / \mathrm{s}$, also rate effects due to limitations on crack propagation contribute to the observed strength increase for all moisture contents and concrete types. Concerning the post peak response for rates $>50 \mathrm{GPa} / \mathrm{s}$, the additional resistance is due to additional micro cracking, the moisture in the capillary pores and the limited crack propagation velocity.
\end{abstract}

\section{INTRODUCTION}

The fracture behaviour of concrete is represented in the load-deformation relation which shows the response up to maximum strength as well as the post-peak response up to complete failure. Dynamic tests performed by the authors demonstrate an extensive rate effect on the tensile strength as well as the post-peak behaviour beyond loading rates of about $50 \mathrm{GPa} / \mathrm{s}$ (strain rates $>1 / \mathrm{s}$ ).

The causes for the extensive rate effects beyond $50 \mathrm{GPa} / \mathrm{s}$ are under discussion. Possible explanations for the observed rate effects on the fracture behaviour are (i) the influence of (structural) inertia forces in the fracture zone which are generated when the material starts to weaken by micro-cracking, (ii) inertia at microlevel in the pre-peak phase and also in the softening phase, due to limitations in crack initiation or crack propagation, (iii) additional micro-cracking and (iv) enhanced resistance by moisture in the pores. The authors contributed to the discussion by their instrumented SHB and spalling tests. The authors showed that the structural inertia effects in the fracture zone do not contribute to the enhanced maximum strength and only contribute to a small extent to the higher fracture resistance at high loading 
rates. Also, experimental data on the fracture patterns shows that the increase in microcracking is limited. Therefore, the moisture in the pores and the inertia at micro-level are believed to be the main causes for the enhanced strength and failure behaviour.

The discussion in this paper focuses on the influence of moisture on the dynamic resistance. In section 2 theoretical background on the moisture effect is given to motivate the selected parameter in the test campaign which is given in section 3. The experimental results and the discussion are given in sections 4, 5 and 6 addressing the rate effects on strength, fracture energy, facture patterns and the loaddeformation curve. The discussion on decisive mechanisms is presented in section 7 . The focus in this section is on tensile strength. Section 8 gives the concluding remarks.

\section{MOISTURE}

The effect of moisture on the dynamic tensile response of concrete has been studied by several researchers theoretically as well as experimentally $[1,2,3]$.

Most dynamic data collected from literature is on tensile strength. The rate effect on tensile strength is usually quantified as a Dynamic Increase Factor, which is the dynamic strength divided by the static strength. Since the absolute static tensile strength decreases with increasing moisture content, interpretation of the influence of moisture on the rate dependency of tensile strength by using only the DIF might lead to incorrect conclusions. Therefore, to analyze the mechanisms we recommend to focus on absolute values.

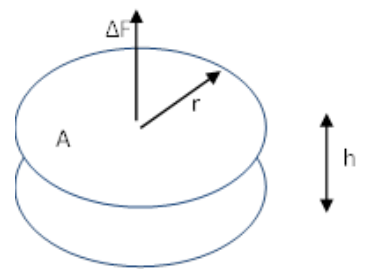

Figure 1: Stefan effect between plane and parallel platens

There is general agreement on the basic mechanism behind the rate effects due to moisture: i.e. the so called Stefan effect. When moisture is present between two plane and parallel platens with a distance $\mathrm{h}$, an opposing force is induced when the platens are separated with a velocity $\dot{h}$ (see Figure 1). For this geometry the Stefan effect, represented by the opposing force, is given by:

$$
\Delta F=\frac{3 \cdot \pi \cdot \eta \cdot r^{4}}{2 \cdot h^{3}} \dot{h}
$$

with $\eta$ the viscosity, $\mathrm{r}$ the radius, $\dot{h}$ the separating velocity and $h$ the distance between the platens.

From this equation it emerges that the dynamic resisting stress is proportional to the velocity, but is most sensitive to the platens distance. Transposing the Stefan effect to concrete with a pore structure, the parameters that govern the ,moisture rate effect are: pore diameter (pore size distribution), pore density (porosity), moisture volume (pore saturation level) and the deformation rate (loading rate). In [4] the authors developed a simple model to quantify the moisture rate effect based on these parameters.

From the Stefan effect and the pore structure of concrete it emerges that the following parameters should be varied in an experimental campaign to study the rate effect due to moisture: (i) loading or strain rate, (ii) moisture content and (iii) the pore structure.

\section{EXPERIMENTAL PROGRAMMME}

\subsection{Test matrix}

To study the influence of the moisture content and pore structure on the rate dependency, different moisture contents and concrete types are used and tested at three loading rates.

Table 1: Test matrix

\begin{tabular}{l|l|l|l|l|l|l}
\hline & \multicolumn{3}{|c|}{ Portland cement concrete } & \multicolumn{3}{l}{ BFS cement concrete } \\
\cline { 2 - 7 } & Normal & Dry50 & Wet & Normal & Dry50 & Wet \\
\hline Static & $*$ & $*$ & $*$ & $*$ & & $*$ \\
\hline SHB & $*$ & $*$ & $*$ & $*$ & & $*$ \\
\hline MSHB & $*$ & $*$ & $*$ & $*$ & & $*$ \\
\hline
\end{tabular}


To study the effect of the pore structure, Portland cement concrete is compared with Blast Furnace Slag (BFS) cement concrete, which has less capillary pores compared to Portland concrete. The test matrix is shown in Table 1.

\subsection{Concrete compositions and curing conditions}

The concrete compositions of the Portland cement concrete and Blast Furnace Slag cement concrete used are presented in Table 2.

Table 2: Concrete compositions

\begin{tabular}{l|l|l|l|l}
\hline $\begin{array}{l}\text { Type } \\
\text { cement }\end{array}$ & $\begin{array}{c}\text { Cement } \\
{\left[\mathrm{kg} / \mathrm{m}^{3}\right]}\end{array}$ & $\begin{array}{c}0-4 \mathrm{~mm} \\
{\left[\mathrm{~kg} / \mathrm{m}^{3}\right]}\end{array}$ & $\begin{array}{c}4-8 \mathrm{~mm} \\
{\left[\mathrm{~kg} / \mathrm{m}^{3}\right]}\end{array}$ & $\begin{array}{c}\text { W/c ratio } \\
{[-]}\end{array}$ \\
\hline Portland & 375 & 1268 & 543 & 0.5 \\
\hline BFS & 375 & 1248 & 535 & 0.5 \\
\hline
\end{tabular}

The three different moisture levels and curing conditions are:

- "Normal" condition: specimens are stored under controlled conditions of $20^{\circ} \mathrm{C}$ and $50 \%$ relative humidity $(\mathrm{RH})$;

- "Wet" condition: specimens are submersed in water;

- "Dry-50" condition: specimens are dried in an oven of $50^{\circ} \mathrm{C}$ and $15 \% \mathrm{RH}$.

The specimens are cylindrical with a diameter of $74 \mathrm{~mm}$. The length of the specimen is $100 \mathrm{~mm}$ for the static and SHB tests and $300 \mathrm{~mm}$ for the MSHB tests. A notch is applied to ensure a single fracture zone.

\subsection{Pore structure and moisture distribution}

To determine the porosity, pore distribution and saturation level for both types of concrete and the three moisture levels Mercury Intrusion Porosimetry (MIP) and Nuclear Magnetic Resonance (NMR) were applied respectively.

First the total porosity of the two types of concretes is determined by MIP. From the results it is concluded that the total porosity of Portland cement concrete is 0.10 and the total porosity of BFS cement concrete is 0.12 .
Next, the pore size distribution is obtained from NMR tests. The results for wet concrete are shown in Figure 2. The parameter a.u., obtained from the NMR tests, represents the volume.

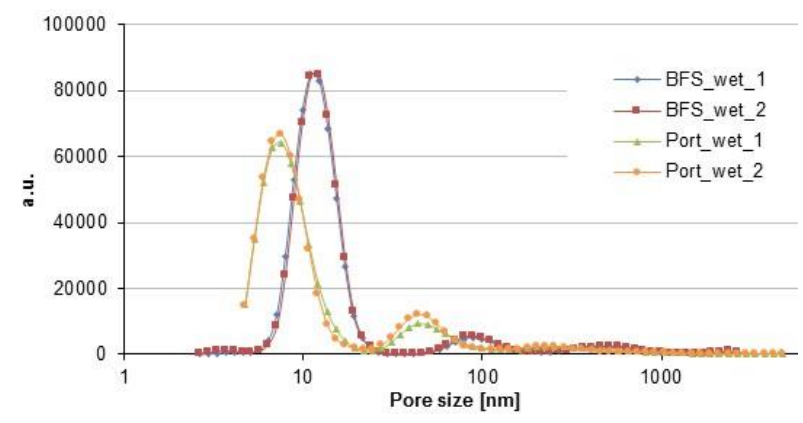

Figure 2: Pore size distribution Portland vs BFS cement concrete (a.u. represents volume)

Figure 2 shows that the diameter of the capillary and gel-pores is larger in BFS cement concrete than in Portland cement concrete. When the absolute volume of filled pores is regarded (see Table 3), the results show that the volume of gel pores is higher for BFS cement concrete (23.50 vs 39.51 ) and that the volume of capillary pores is more or less the same as for Portland cement concrete (25.07 vs 23.59).

Table 3: Volume of filled pores (parameter a.u. from NMR represents volume)

\begin{tabular}{l|l|l|l}
\hline Condition & $\begin{array}{l}\text { Total } \\
\text { volume } \\
\text { filled pores } \\
\text { [a.u. x10 } 6 \text { ] }\end{array}$ & $\begin{array}{l}\text { Volume } \\
\text { filled Gel } \\
\text { pores } \\
\text { [a.u. x106] }\end{array}$ & $\begin{array}{l}\text { Volume } \\
\text { filled Cap } \\
\text { pores } \\
\text { [a.u. x106] }\end{array}$ \\
\hline Port-dry50 & 3.71 & 0.77 & 2.94 \\
Port-normal & 16.71 & 13.32 & 3.39 \\
Port-wet & 48.57 & 23.50 & 25.07 \\
\hline BFS-dry50 & 8.84 & 7.07 & 1.77 \\
BFS-normal & 33.20 & 28.83 & 4.37 \\
BFS-wet & 63.10 & 39.51 & 23.59 \\
\hline
\end{tabular}

For the two types of concrete and the different conditions, the average diameter of the filled capillary and gel pores is determined. The results are summarized in Table 4 and Table 5. 
Table 4: Average diameter of filled capillary pores

\begin{tabular}{l|l|l|l}
\hline & $\begin{array}{l}\emptyset \text { Dry-50 } \\
{[\mathrm{nm}]}\end{array}$ & $\begin{array}{l}\varnothing \text { Normal } \\
{[\mathrm{nm}]}\end{array}$ & $\begin{array}{l}\emptyset \text { Wet } \\
{[\mathrm{nm}]}\end{array}$ \\
\hline Portland & 55 & 50 & 44 \\
\hline BFS & - & 63 & 89 \\
\hline
\end{tabular}

Table 5: Average diameter of filled gel pores

\begin{tabular}{l|l|l|l}
\hline & $\begin{array}{l}\varnothing \text { Dry-50 } \\
{[\mathrm{nm}]}\end{array}$ & $\begin{array}{l}\varnothing \text { Normal } \\
{[\mathrm{nm}]}\end{array}$ & $\begin{array}{l}\varnothing \text { Wet } \\
{[\mathrm{nm}]}\end{array}$ \\
\hline Portland & 12.5 & 6.5 & 7.0 \\
\hline BFS & - & 10.0 & 11.5 \\
\hline
\end{tabular}

\subsection{Testing devices}

The tensile tests are performed with three testing devices. A static loading device (loading rate $\dot{\sigma}=1 \cdot 10^{-4} \mathrm{GPa} / \mathrm{s}$ ), a gravity driven Split Hopkinson bar $(\dot{\sigma} \approx 50 \mathrm{GPa} / \mathrm{s})$ and a Modified Split Hopkinson bar which is a spalling test setup $(\dot{\sigma}>1000 \mathrm{GPa} / \mathrm{s})$ (see Figure 3). These devices are extensively described in previous publications, e.g. $[5,6]$.

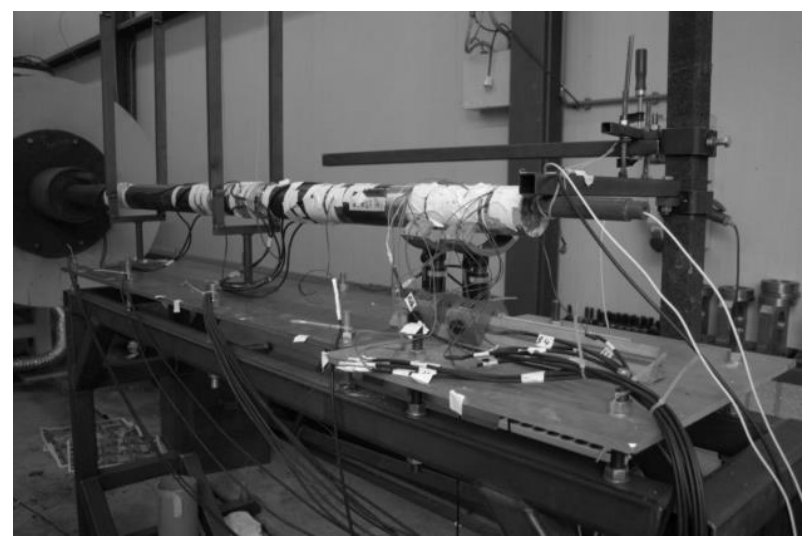

Figure 3: Modified Split Hopkisnon Bar at TNO

For the dynamic tests (SHB and MSHB), not only the strains but also the deformation of the failure zone are directly recorded. The strains are recorded before as well as beyond the fracture zone. The direct measurement of the strains and deformations enables us to derive the load-deformation curve. The top of this curve reflects the tensile strength and the area under this curve represents the fracture energy. Therefore, the load-deformation curves for different loading rates give information on the rate effect on tensile strength and fracture energy. The shape of the softening curve reflects the fracture process. At the top of the curve micro cracking has started and tensile strength has been reached. During softening, the micro cracks grow, coalesce and finally form a macro crack.

In order to relate the mechanical response to the fracture process, the crack patterns are also analyzed and quanitfied (see section 4, 5 and 6 for the results on tensile strength, fracture energy and fracture process).

\section{TENSILE STRENGTH}

\subsection{Strength data}

The tensile strength in the dynamic tests is derived from the strain recordings beyond the final fracture plane. So it is based on the residual stress pulse that passed the fracture zone. The details of the applied diagnostics and data analyses are described in [4, 7] and not repeated in this paper.

Table 6: Tensile strength data for PC

\begin{tabular}{|c|c|c|c|c|c|}
\hline & Series & $\begin{array}{l}\dot{\varepsilon} \\
{[1 / \mathrm{s}]}\end{array}$ & $\begin{array}{l}\mathrm{f}_{\mathrm{t}} \\
{[\mathrm{MPa}]}\end{array}$ & $\begin{array}{l}\text { St.dev. } \\
{[\mathrm{MPa}]}\end{array}$ & $\begin{array}{l}\mathrm{f}_{\mathrm{t}} / \mathrm{f}_{\text {stat }} \\
{[-]}\end{array}$ \\
\hline Nor- & Stat & $2.7 \cdot 10^{-6}$ & 3.30 & 0.32 & 1.0 \\
\hline \multirow[t]{2}{*}{ mal } & SHB & 1.1 & 5.58 & 0.21 & 1.7 \\
\hline & MSHB & 47.3 & 10.87 & 0.90 & 3.3 \\
\hline \multirow[t]{3}{*}{ Dry } & Stat & $2.7 \cdot 10^{-6}$ & 3.05 & 0.43 & 1.0 \\
\hline & SHB & 1.1 & 4.73 & 0.53 & 1.6 \\
\hline & MSHB & 40.7 & 8.39 & 0.80 & 2.8 \\
\hline \multirow[t]{3}{*}{ Wet } & Stat & $2.6 \cdot 10^{-6}$ & 2.05 & 0.26 & 1.0 \\
\hline & SHB & 1.0 & 6.35 & 0.30 & 3.1 \\
\hline & MSHB & 58.1 & 17.14 & 2.50 & 8.4 \\
\hline
\end{tabular}

Table 7: Tensile strength data for BFSC

\begin{tabular}{llllll}
\hline & Series & $\dot{\varepsilon}$ & $\begin{array}{l}\mathrm{f}_{\mathrm{t}} \\
{[\mathrm{MPa}]}\end{array}$ & $\begin{array}{l}\text { St.dev. } \\
{[\mathrm{MPa}]}\end{array}$ & $\begin{array}{l}\mathrm{f}_{\mathrm{t}} / \mathrm{f}_{\text {stat }} \\
{[-]}\end{array}$ \\
\hline Nor- & Stat & $1.4 \cdot 10^{-6}$ & 2.54 & 0.37 & 1.0 \\
mal & SHB & 0.8 & 4.10 & 0.54 & 1.6 \\
& MSHB & 42.7 & 9.87 & 2.01 & 3.9 \\
\multirow{2}{*}{ Wet } & Stat & $1.4 \cdot 10^{-6}$ & 3.25 & 0.51 & 1.0 \\
& SHB & 1.3 & 6.02 & 0.47 & 1.9 \\
& MSHB & 59.5 & 15.20 & 1.07 & 4.7 \\
\hline
\end{tabular}


The strength data for Portland cement concrete (PC) are given in Table 6 and for Blast Furnace Slag cement concrete (BFSC) in Table 7.

\subsection{Discussion strength data}

The static tensile strength for wet concrete is lower than for normal and dry conditions. This can be explained by the Munich model from Wittmann [8]. The Munich model describes how concrete is weakened by the water molecules in the gel pores resulting in a lower static strength.

The main observations on rate effects from the strength data:

- Wet concrete exhibits a larger strength increase than normal and dry concrete, for Portland as well as BFS cement concrete and for the high as well as the moderate loading rate regime.

- Water in capillary pores causes the rate effects in the moderate loading rate regime; for instance, the absolute strength increase for normally cured Portland and BFS cement concrete is similar, as is the volume of filled capillary pores.

\section{FRACTURE ENERGY}

\subsection{Fracture energy data}

The fracture energy $G_{f}$ is determined by the resistance of the material to micro-cracking and the energy absorbed during micro and macro cracking. The fracture energy has to be determined from a single fracture zone. A single fracture zone is dictated by a single macro crack but comprehends not only the single macro crack but also the involved micro cracks in the adjacent material. To ensure only one fracture zone will be initiated, all the specimens used have a notch (see section 3 ). For the experiments, the fracture energy is determined by calculating the area under the stress-displacement and stress-deformation curves. The average results for PC as well as BFSC are summarized in Table 8 and Table 9.
Table 8: Fracture energy data for PC

\begin{tabular}{llllll}
\hline & Series & $\dot{\varepsilon}$ & $\mathrm{G}_{\mathrm{f}}$ & $\begin{array}{l}\text { St.dev. } \\
{[1 / \mathrm{s}]}\end{array}$ & $\begin{array}{l}\mathrm{G}_{f} / \mathrm{G}_{\mathrm{f}, \text { stat }} \\
{[\mathrm{N} / \mathrm{m}]}\end{array}$ \\
\hline \multirow{2}{*}{ Nor- } & Stat & $2.7 \cdot 10^{-6}$ & 120.2 & 12.1 & 1.0 \\
mal & SHB & 1.1 & 133.2 & 9.7 & 1.1 \\
& MSHB & 47.3 & 551.3 & 176.4 & 4.6 \\
\hline \multirow{2}{*}{ Dry } & Stat & $2.7 \cdot 10^{-6}$ & 105.5 & 21.3 & 1.0 \\
& SHB & 1.1 & 133.4 & 33.1 & 1.3 \\
& MSHB & 40.7 & 572.5 & 92.7 & 5.4 \\
\multirow{2}{*}{ Wet } & Stat & $2.6 \cdot 10^{-6}$ & 80.3 & 8.2 & 1.0 \\
& SHB & 1.0 & 157.5 & 44.3 & 2.0 \\
& MSHB & 58.1 & 1274 & 322.3 & 15.9 \\
\hline
\end{tabular}

Table 9: Fracture energy data for BFSC

\begin{tabular}{|c|c|c|c|c|c|}
\hline & Series & $\begin{array}{l}\dot{\varepsilon} \\
{[1 / \mathrm{s}]}\end{array}$ & $\begin{array}{l}\mathrm{G}_{\mathrm{f}} \\
{[\mathrm{N} / \mathrm{m}]}\end{array}$ & $\begin{array}{l}\text { St.dev. } \\
{[\mathrm{N} / \mathrm{m}]}\end{array}$ & $\begin{array}{c}\mathrm{G}_{\mathrm{f}} / \mathrm{G}_{\mathrm{f} \text {,stat }} \\
{[-]}\end{array}$ \\
\hline \multirow{3}{*}{$\begin{array}{l}\text { Nor- } \\
\text { mal }\end{array}$} & Stat & $1.4 \cdot 10^{-6}$ & 112.4 & 18.5 & 1.0 \\
\hline & SHB & 0.8 & 112.6 & 19.9 & 1.0 \\
\hline & MSHB & 42.7 & 568.9 & 208.2 & 5.1 \\
\hline \multirow[t]{3}{*}{ Wet } & Stat & $1.4 \cdot 10^{-6}$ & 81.1 & 11.7 & 1.0 \\
\hline & SHB & 1.3 & 180.3 & 55.5 & 2.2 \\
\hline & MSHB & 59.5 & 778.4 & 258.9 & 9.6 \\
\hline
\end{tabular}

\subsection{Discussion test data}

The results show for all curing conditions only a mild increase in fracture energy for the moderate loading rates. For the normally conditioned PC and BFSC no increase in fracture energy is found for the moderate regime.

Wet concrete, Portland as well as BFS cement concrete, demonstrates the highest rate effect on relative fracture energy $\left(\mathrm{G}_{\mathrm{f}} / \mathrm{G}_{\mathrm{f} \text {,stat }}\right)$ for the moderate as well as the high loading rate regime.

The absolute fracture energy increase in the moderate regime is higher for BFS than Portland cement concrete. This is contradictory to the tensile strength increase, where the absolute increase is higher for Portland cement concrete. This proves that the increase in fracture energy in the moderate regime is not only caused by the enhanced tensile strength due to moisture, but is also influenced by the 
amount of additional micro cracks. The fact that the fracture energy remains constant while the strength increases in the moderate regime, proves that both mechanisms contribute.

For the high loading rate regime, the fracture energy increases significantly. Normal and dry concrete behave similar, when comparing the Dynamic Increase Factor $\left(D I F=G_{f} / G_{f, s t a t}\right)$ and the absolute values for the fracture energy results. Wet concrete shows a high absolute increase in fracture energy, for PC even higher than for BFSC. From these results it is concluded that moisture and pore structure play an important role for the fracture energy, for the moderate as well as the high loading rate regime.

\section{FRACTURE PROCESS}

\subsection{Load -deformation curves}

In the previous sections the effect of the moisture contents on the dynamic strength and fracture energy was presented. These are keyparameters emerging from the loaddeformation curves which represent the entire fracture process. In the experimental program these curves were derived for all conditions, which provides the opportunity to study the effect of moisture on the fracture process in more detail. The curves are given in Figure 4 to 8 for all curing and loading conditions. To interpret the pre-peak behaviour it should be noted that for the dynamic tests the deformation in the curves represents the inelastic deformation only. In the static tests the elastic deformation is included.

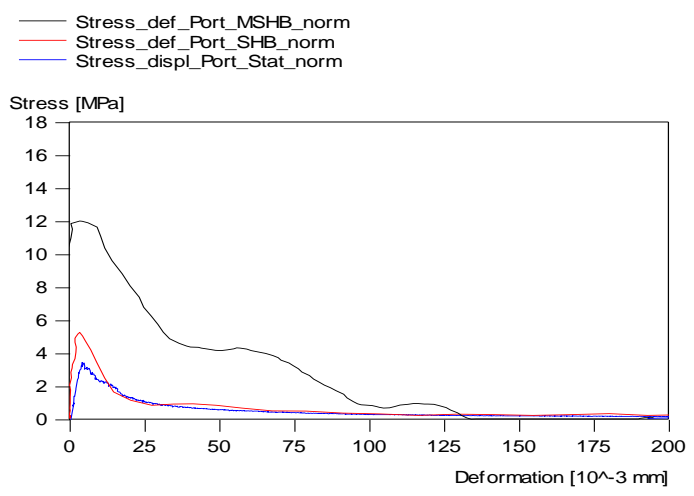

Figure 4: Stress-displacement curve (stat) and stressdeformation curves SHB and MSHB for PC; "normal"

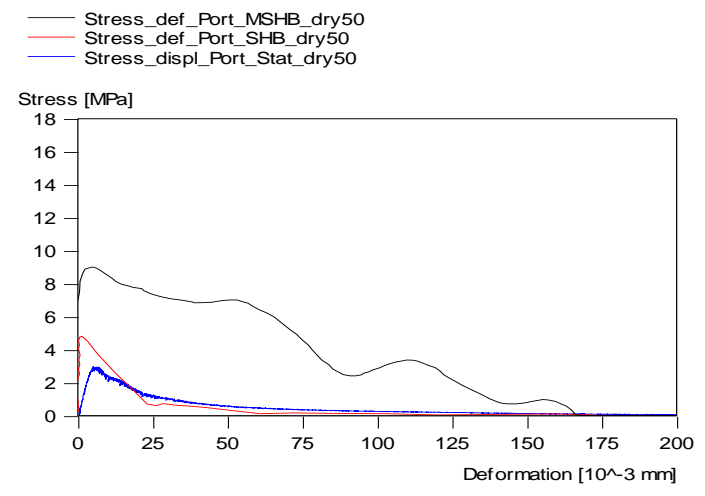

Figure 5: Stress-displacement curve (stat) and stressdeformation curves SHB and MSHB for PC, "Dry"

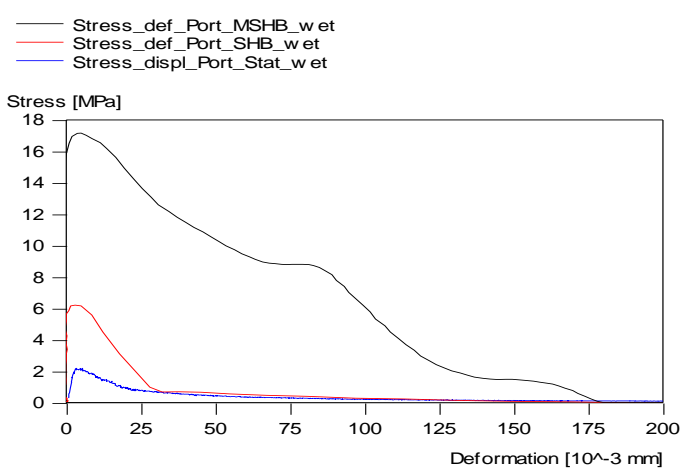

Figure 6: Stress-displacement curve (stat) and stressdeformation curves SHB and MSHB for PC; "Wet"

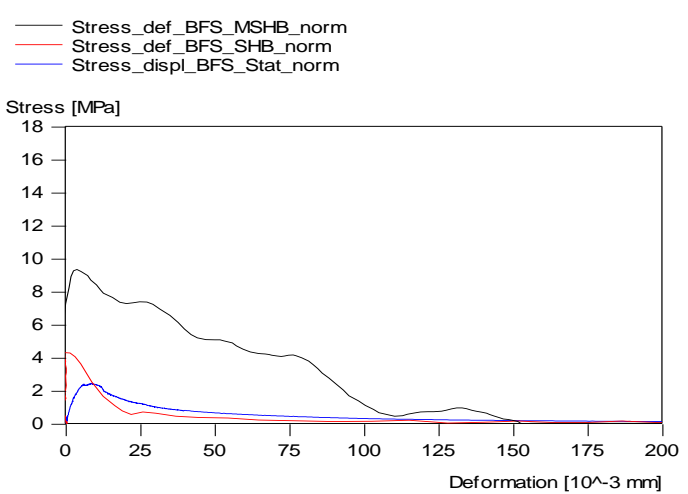

Figure 7: Stress-displacement curve (stat) and stressdeformation curves SHB and MSHB for BFSC "Norm"

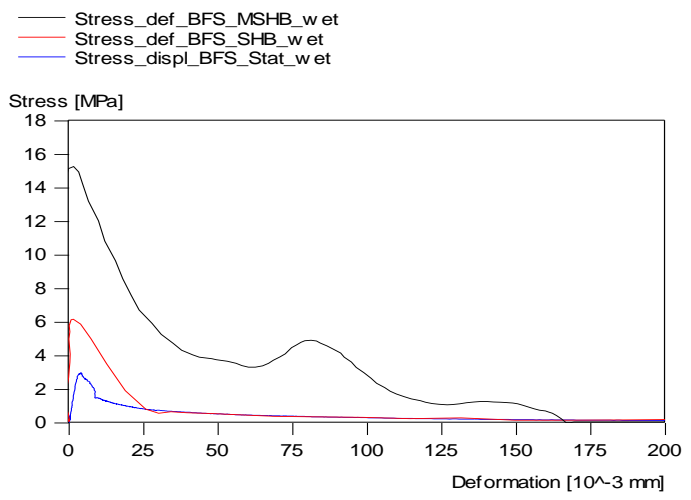

Figure 8: Stress-displacement curve (stat) and stressdeformation curves SHB and MSHB for BFSC, "Wet" 
The ascending branches only exhibit minor non-linearity just before the maximum, so the micro-cracking is very limited. In the post-peak response, the first branch of the softening curve represents the formation and coalescence of the micro cracks and the second branch reflects the final formation and opening of the macro crack.

Reviewing the results, the general conclusion is that moisture in the pores causes an increase in fracture energy. The main observations are as follows.

For the Static and moderate loading rate regime:

- The softening curve has two branches for all curing conditions.

- For wet concrete, PC as well as BFSC, the transition to the second part of the softening curve tends to occur at slightly larger deformation. This might be due to a larger amount of additional micro cracks compared to normal and dry concrete.

- The maximum deformation, i.e. the full macro crack opening, is about $150 \mu \mathrm{m}$ and is not affected by the curing conditions or the loading rate up to $50 \mathrm{GPa} / \mathrm{s}$. Apparently, the failure process itself is similar.

Observations for the high loading rate regime:

- For the high loading rate regime the loaddeformation curve changes. The transition from micro cracking to the formation of the final macro crack is less distinct. The formation of the final macro crack occurs at larger deformation. The concrete responds much less brittle, but the maximum deformation is hardly affected. Only a slight increase $(150-175 \mu \mathrm{m})$ is observed, which indicate that also at the high loading rate one single, dominant macro crack is formed.

- Moisture has a distinct effect on the fracture process. For PC the influence of moisture is very distinct up to failure. For wet BFSC the additional resistance is observed only in the first part of the softening curve. An explanation might be found in the smaller amount of additional micro cracks.
The curves represent the fracture process, but do not give the explanation for the enhanced resistance at higher rates. Whether this increase is due to additional micro cracking, moisture and/or inertia effects can only be determined when studying the experimental results in combination with the fracture patterns. The characteristics of the fracture patterns are presented in the next section.

\subsection{Fracture characteristics}

Geometrical characteristics of the fracture zone have been derived from the specimens after the static, Split Hopkinson Bar and Modified Split Hopkinson Bar tests are completed for both concrete types and all conditions. The fracture patterns are captured and exposed by using fluorescent epoxy. The fracture patterns are studied qualitatively as well as quantitatively.

From the qualitative results of the static and SHB tests on Portland cement concrete it can be concluded that there are only minor differences between the fracture patterns for the static and medium loading rate regime for all conditions (see Figure 9 - Figure 11).

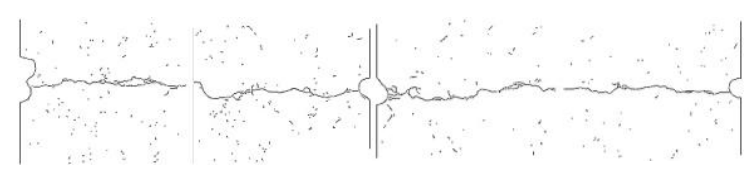

Figure 9: PC, "Normal": (left) static, (right) SHB

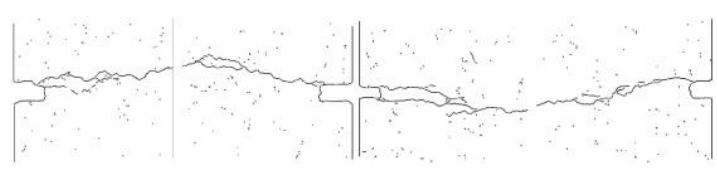

Figure 10: PC, "Dry": (left) static, (right) SHB

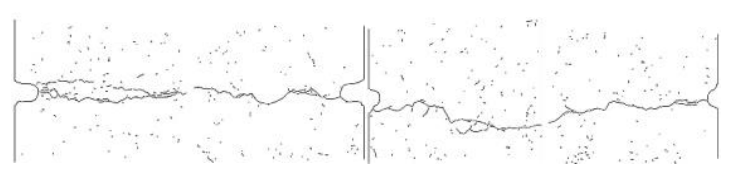

Figure 11: PC, "Wet": (left) static, (right) SHB

The fracture patterns for the high loading rates differ from the static and medium loading rate patterns, see Figure 12 and Figure 13. For all curing conditions the length of individual micro cracks in the fracture zone highly increase. For wet PC at high loading rates the 
amount and length of the individual micro cracks, not connected to the macro crack, are much larger than for dry and normal PC. Micro cracks, parallel to the macro crack, seem to have formed during fracture. Note that for the various curing and loading conditions, the features of the crack patterns for the BFSC were similar as for the PC. Therefore these are not given in this paper.

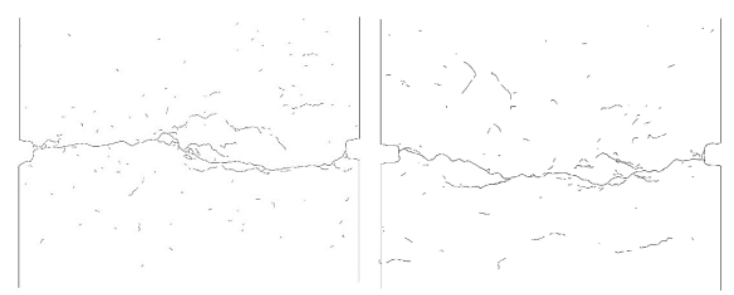

Figure 12: PC, MSHB: (left) "Normal", (right) "Dry"

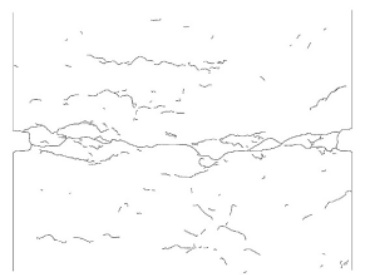

Figure 13: PC, MSHB: "Wet".

To obtain quantitative results on fracture lengths and widths of the fracture zone, the crack patterns are manually digitalized and analyzed.

The cracks are subdivided into:

(1) macro crack, which is the crack where physical separation of the two parts of the specimen has taken place.

(2) connected micro cracks, which are connected to the macro crack.

(3) isolated micro cracks, which are not connected to the macro crack but found isolated in the concrete sample.

The fracture characteristics, total length of cracks, amount of cracks and width of the fracture zone, are determined for Portland cement concrete (PC) and Blast Furnace Slag cement concrete (BFSC) and all curing conditions. The results are visualized in Figures 14 and 15.

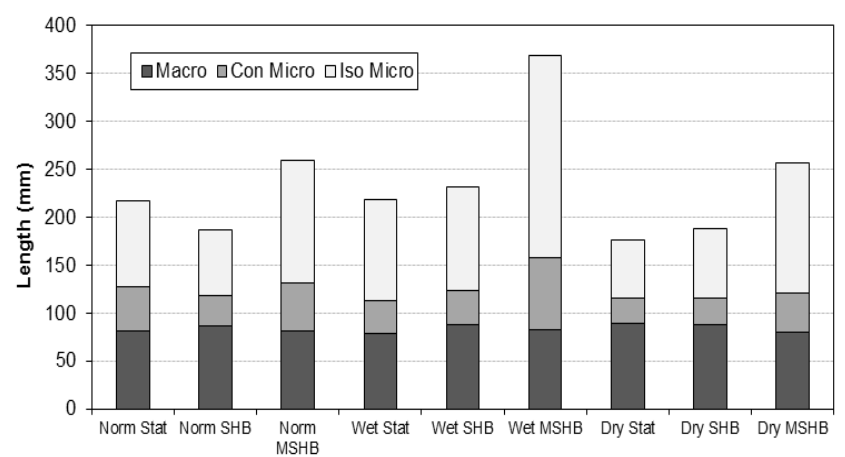

Figure 14: Average total length of fracture for Static, SHB and MSHB test, PC (normal, dry50 and wet).

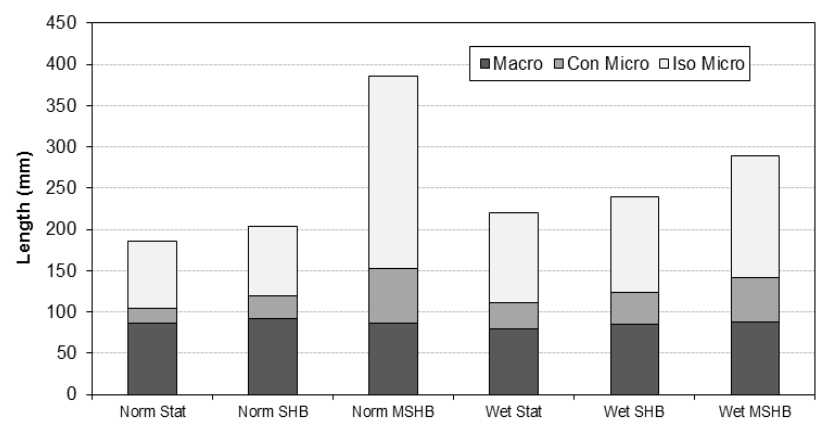

Figure 15: Average total length of fracture for Static, SHB and MSHB test, BFSC (normal and wet).

From the data on fracture lengths the following conclusions can be drawn;

Static and moderate loading rate regime:

- The length of the final macro crack is not affected by loading rate or curing condition. $\mathrm{PC}$ and BFSC also show similar results on macro crack lengths. Apparently, the macro crack length is mainly dominated by concrete structure and aggregate grading, which is similar for both concrete types.

- For Portland as well as BFS cement concrete, up to a loading rate of $50 \mathrm{GPa} / \mathrm{s}$, additional micro cracking is not substantial for all curing conditions compared to the static loading rate. The total length of micro cracks is even slightly reduced for normal Portland cement concrete.

- The increase in fracture energy in the moderate regime is not linearly proportional to the total length of the additional micro cracks. This is most obvious from the wet Portland cement concrete results. The fracture length increases with a factor 1.1 
compared to the static loading rate, while the fracture energy increases with a factor 2.0 .

- The fracture energy increase with a factor 2 for wet Portland and BFS cement concrete in the moderate regime. The length of additional micro cracks is only slightly increasing for the wet concrete types. Micro-inertia only plays a role for loading rates larger than $50 \mathrm{GPa} / \mathrm{s}$ (see discussion in section 7). Therefore, in the moderate regime, the increase in fracture energy is probably also caused by the water in the capillary pores providing additional resistance to crack growth.

High loading rate regime:

- The total length of the macro crack is similar to the moderate regime.

- In the high loading rate regime the total length of micro fracture increases considerably.

- The additional micro crack length is considerable for normally conditioned BFS cement concrete, more than for wet BFS cement concrete. This is contrary to Portland cement concrete, where the wet concrete exhibits a higher increase in micro crack length for the high loading regime. This higher increase is unexpected and cannot be fully explained with the current experimental data.

Besides the data on the crack lengths the analysis also provided data on the width of the fracture zone and the crack density.

Table 10: Average results for WFZ, PC

\begin{tabular}{llllll}
\hline & Series & $\dot{\varepsilon}$ & $\begin{array}{l}\text { WFZ } \\
\mathrm{mac} \\
{[\mathrm{mm}]}\end{array}$ & $\begin{array}{l}\text { WFZ } \\
\mathrm{mac}+\text { con } \\
{[\mathrm{mm}]}\end{array}$ & $\begin{array}{l}\text { WFZ } \\
\text { tot } \\
{[\mathrm{mm}]}\end{array}$ \\
\hline Nor. & Stat & $2.7 \cdot 10^{-6}$ & 4.5 & 6.2 & 6.7 \\
& SHB & 1.1 & 6.3 & 7.4 & 8.1 \\
& MSHB & 47.3 & 6.6 & 8.6 & 19.1 \\
\hline \multirow{2}{*}{ Dry } & Stat & $2.7 \cdot 10^{-6}$ & 7.4 & 7.5 & 8.7 \\
& SHB & 1.1 & 6.8 & 7.6 & 8.8 \\
& MSHB & 40.7 & 6.2 & 7.7 & 43.7 \\
Wet & Stat & $2.6 \cdot 10^{-6}$ & 4.5 & 4.7 & 6.0 \\
& SHB & 1.0 & 7.3 & 7.8 & 9.6 \\
& MSHB & 58.1 & 6.4 & 9.8 & 47.5 \\
\hline
\end{tabular}

Table 11: Average results for WFZ, BFSC

\begin{tabular}{llllll}
\hline & Series & $\dot{\varepsilon}$ & $\begin{array}{l}\text { WFZ } \\
\text { mac } \\
{[\mathrm{mm}]}\end{array}$ & $\begin{array}{l}\text { WFZ } \\
\mathrm{mac}_{\text {con }} \\
{[\mathrm{mm}]}\end{array}$ & $\begin{array}{l}\text { WFZ } \\
\text { tot } \\
{[\mathrm{mm}]}\end{array}$ \\
\hline Nor. & Stat & $1.4 \cdot 10^{-6}$ & 6.5 & 7.5 & 10.5 \\
& SHB & 0.8 & 8.2 & 8.7 & 12.2 \\
& MSHB & 42.7 & 7.0 & 9.7 & 33.2 \\
Wet & Stat & $1.4 \cdot 10^{-6}$ & 5.3 & 6.5 & 10.8 \\
& SHB & 1.3 & 6.0 & 7.2 & 13.0 \\
& MSHB & 59.5 & 7.4 & 9.2 & 18.4 \\
\hline
\end{tabular}

The results on the total Width of the Fracture Zone (WFZ), the width of the macro crack +connected micro crack (WFZ mactcon ) and the width of macro crack zone $\left(\mathrm{WFZ}_{\mathrm{mac}}\right)$ are given in Table 10 and Table 11 for PC and BFSC.

From the data on the width of the fracture zone, the following can be concluded:

Static and moderate loading rate regime:

- The total width of the fracture zone (WFZ) is only moderately affected by loading rate. The rate dependency is most distinct for the wet condition.

High loading rate regime:

- The width of fracture zone (WFZ) increases significantly.

- The WFZ increases more than the total length of cracks which means that the crack density is decreasing for the high loading rate regime. This effect is more pronounced for Portland cement concrete than for BFS cement concrete.

At high loading rates the width of the fracture zone (WFZ) is much wider and the process of micro-cracking occurs also at some distance of the macro crack. The additional micro-cracking during the formation of the final macro crack explains why for the stressdeformation curve of the MSHB tests the two branches are not as distinctive as for the moderate and static loading rate.

Although the width of the total fracture zone increases considerably for the high loading rate regime, most of the damage (approximately 
95\%) still occurs around the macro crack with connected micro cracks. This observation is important for numerical simulations where the internal length scale has to be introduced. This should be linked to the width of the macro crack with connected micro cracks instead of the total width of the fracture zone. The width of the macro crack with connected micro cracks is hardly affected by the loading rate. Subsequently, the internal length scale does not change with increasing loading rate.

\section{DISCUSSION ON DECISIVE MECHANISMS}

\subsection{Tensile strength}

In the previous sections the results on tensile strength and fracture behaviour are presented for all moisture contents and the two concrete types. In this paragraph the observed rate effects are related to the mechanisms which might lead to rate effects in concrete. To recall, for the dynamic tensile strength the observed increase in strength is believed to be due to:

(1) the influence of (structural) inertia forces which are generated when the material starts to weaken by micro-cracking in the fracture zone.

(2) influence of inertia at micro-level which delays crack initiation.

(3) influence of inertia at micro-level which delays crack propagation.

(4) the viscous behaviour of the material due to the water in the pores (Stefan effect).

Ad (1) "the structural inertia of the fracture zone". The recording of the deformation of the fracture zone provided data on the separation velocity and -acceleration in time. The concrete resistance during the whole loading process is recorded beyond the failure zone and depends on the stresses transmitted through this zone. Before the maximum strength is reached the pre-peak non-linearity is very limited and, taking the wave equations into account, the incident stress wave can be fully transferred although some time delay will occur (for details see [4]). Therefore, it is concluded that the recorded dynamic strength is the 'true' dynamic strength and not influenced by structural inertia of the fracture zone.

Ad (2) "delayed crack initiation due to micro inertia". It has been shown by the authors $[4,7]$ that only beyond a loading rate of $5000 \mathrm{GPa} / \mathrm{s}$ crack initiation can be delayed due to inertia effects at the tips of representative cracks in concrete. The performed tests were below this rate.

Ad (3) "delayed crack propagation due to micro inertia". The authors made a simple model to estimate when limited crack velocities will affect the strength. The threshold for the loading rate depends on the static strength, $f_{t}$, the representative crack size, $a$, and the limited crack velocity, $\dot{a}$ (maximum $1000 \mathrm{~m} / \mathrm{s}$ ), and is given in (eq 2):

$$
\dot{\sigma} \geq \frac{0.1 f_{t} \cdot \dot{a}}{\Delta a}
$$

The minimum tensile static strength is approximately 2 MP, for wet Portland cement concrete. With a static strength of $2 \mathrm{MPa}$ and using a maximum crack velocity of $1000 \mathrm{~m} / \mathrm{s}$, the threshold for effects due to delayed crack propagation is at loading rates of $7-40 \mathrm{GPa} / \mathrm{s}$. This is about the same range as the medium loading rate of the SHB tests. The effects of delayed crack propagation due to micro inertia, therefore, will probably only occur for the high loading rate regime and will only minimally influence the results in the moderate loading rate regime.

From foregoing analysis it is concluded that beyond loading rates in the range of $10-40 \mathrm{GPa} / \mathrm{s}$, rate effects due to limitations on the crack velocity and therefore limitations on crack propagation contribute to the observed strength increase for all moisture contents and concrete types. This means that for the medium loading rate regime, micro-inertia only plays a minor role and the main cause for the enhanced tensile strength increase is probably the viscous behaviour of concrete. 
In Table 12 the tensile strength results are summarized and the dynamic increase is quantified for the moderate as well as the high loading rate regime. The table also gives the data on the pore structure The total volume of water present in the gel- and capillary pores is defined with the NMR-output variable (a.u.) and represents the volume of the filled pores.

Table 12: Summary tensile strength and pore data

\begin{tabular}{|c|c|c|c|c|c|}
\hline $\begin{array}{l}\text { Concr./ } \\
\text { cond. }\end{array}$ & $\begin{array}{l}\mathrm{f}_{\mathrm{t}, \mathrm{stat}} \\
\mathrm{MPa}\end{array}$ & $\begin{array}{l}\mathrm{f}_{\mathrm{f}, \mathrm{SHB}} \\
\mathrm{MPa}\end{array}$ & $\begin{array}{l}\mathrm{f}_{\mathrm{t}, \mathrm{MSHB}} \\
\mathrm{MPa}\end{array}$ & $\begin{array}{l}\Delta \mathrm{f}_{\mathrm{t}} \\
\mathrm{SHB} \\
\mathrm{MPa}\end{array}$ & $\begin{array}{l}\Delta \mathrm{f}_{\mathrm{t},} \\
\mathrm{MSHB} \\
\mathrm{MPa}\end{array}$ \\
\hline P-norm & 3.30 & 5.58 & 10.87 & 2.3 & 7.6 \\
\hline P-dry50 & 3.05 & 4.73 & 8.39 & 1.7 & 5.3 \\
\hline P-wet & 2.05 & 6.35 & 17.14 & 4.3 & 15.1 \\
\hline $\begin{array}{l}\text { BFS- } \\
\text { norm }\end{array}$ & 2.54 & 4.10 & 9.87 & 1.6 & 7.3 \\
\hline $\begin{array}{l}\text { BFS- } \\
\text { wet }\end{array}$ & 3.25 & 6.02 & 15.20 & 2.8 & 12.0 \\
\hline \multicolumn{2}{|c|}{ Concr./ cond. } & \multicolumn{2}{|c|}{$\begin{array}{l}\text { Gel-pores } \\
{\left[\text { a.u. } \times 10^{6}\right]}\end{array}$} & \multicolumn{2}{|c|}{$\begin{array}{l}\text { Cap-pores } \\
{\left[\text { a.u. } \times 10^{6}\right]}\end{array}$} \\
\hline \multicolumn{2}{|l|}{ P-normal } & \multicolumn{2}{|c|}{13.32} & \multicolumn{2}{|c|}{3.39} \\
\hline \multicolumn{2}{|l|}{ P-dry50 } & \multicolumn{2}{|l|}{0.77} & \multicolumn{2}{|l|}{2.94} \\
\hline \multicolumn{2}{|l|}{ P-wet } & \multicolumn{2}{|c|}{23.50} & \multicolumn{2}{|l|}{25.07} \\
\hline \multicolumn{2}{|c|}{ BFS-normal } & \multicolumn{2}{|c|}{28.83} & \multicolumn{2}{|l|}{4.37} \\
\hline \multicolumn{2}{|l|}{ BFS-wet } & 39.51 & & \multicolumn{2}{|l|}{23.59} \\
\hline
\end{tabular}

When considering the strength increase in the moderate regime ( $\Delta \mathrm{ft}$,sHB see Table 12$)$ and the moisture present in the gel- and capillary pores, it is concluded that the water in the capillary pores and not the gel-pores causes the increase in tensile strength:

- The dry PC and normal BFSC have the same increase in tensile strength in the moderate regime (1.7 $\mathrm{MPa}$ and $1.6 \mathrm{MPa})$, while the amount of filled gel-pores is very different.

- The differences in amount of filled gelpores is high, when comparing normal and dry PC, while the strength increase is limited.

- The strength increase of wet PC is much higher than for normal PC, while the difference in amount of filled gel pores is small. The difference in amount of filled capillary pores, however, is high.

\subsection{Fracture energy and post peak.}

The results on fracture behaviour and fracture characteristics are presented in the previous sections for all moisture contents and the two concrete types. For loading rates beyond $50 \mathrm{GPa} / \mathrm{s}$ the rate effect on fracture energy is much larger than on the tensile strength. The large additional resistance reflected in the stress-deformation curves of the dynamic tests can be due to four different phenomena:

(1) Structural inertia in the post-peak response.

(2) Additional micro cracking.

(3) Inertia at micro-level which delays the crack propagation in the pre-peak as well as in the softening phase.

(4) Enhanced resistance by moisture in the pores or micro cracks in the pre-peak and the post-peak phase.

Ad (1) "structural inertia of FZ". Using the data on the separation acceleration and the width of the fracture zone, the contribution of the structural inertia of the fracture zone has been quantitatively estimated in [4]. The results have shown that the derived fracture energy and stress-deformation curves for the high loading regime (> $50 \mathrm{GPa} / \mathrm{s})$ are only slightly affected by structural inertia effects of the fracture zone. Only the observed 'bumps' in the stressdeformation curves are reduced when results are corrected for structural inertia effects.

Ad (2) "additional micro cracking". The observed increase in fracture energy and the enhanced resistance can only be partly attributed to additional micro cracking (see Figures 14 and 15 and Tables 8 and 9).

The most probable explanation for the enhanced fracture resistance is, therefore, the additional resistance due to the moisture in the capillary pores combined with the limited crack propagation velocity. For a more detailed discussion of the mechanisms behind the rate effects on the fracture process, see [4]. 


\section{CONCLUDING REMARKS}

The applied testing and diagnostic techniques provide true strength data. The derived fracture energy and stress-deformation curves are only in the high loading regime $(>50$ $\mathrm{GPa} / \mathrm{s}$ ) slightly affected by structural inertia effects of the fracture zone.

The moisture volume, porosity and pore structure have a large influence on the dynamic response for all loading regimes. Only moisture in the capillary pores lead to enhanced dynamic strength and post-peak resistance.

The limitation in crack propagation velocity leading to enhanced resistance will only occur for loading rates beyond $50 \mathrm{GPa} / \mathrm{s}$.

For loading rates larger than $50 \mathrm{GPa} / \mathrm{s}$ the rate effect on fracture energy is much larger than on the tensile strength. This increase can only partly be attributed to additional micro cracking. The most probable explanation is the additional resistance due to the moisture in the capillary pores combined with delayed crack propagation because of the limited crack propagation velocity.

\section{REFERENCES}

[1] Cadoni, E., Labibes, K., Albertini, C., Berra, M. and Gian-grasso, M. 2001. Strain rate effect on the tensile behaviour of concrete at different relative humidity levels. Materials and Structures 34: 21-26.

[2] Ross, A.C., Jerome, D.M., Tedesco, J.W. and Hughes, M.L. 1996. Moisture and strain rate effects on concrete strength. ACI Materials Journal 93(3): 293-300.

[3] Toutlemonde, F. and Rossi, P. 1998. Free water in concrete pores: an Attempt of physical explanation of concrete behavior. Concrete and Blast effects American concrete institute, Michigan.

[4] Vegt, I. 2016. Concrete in dynamic tension: the fracture process. Thesis TUDelft. In press.

[5] Vegt, I., Weerheijm, J. and Van Breugel, K. 2007. The fracture energy of concrete under impact tensile loading- a new experimental technique. Proceedings of the CONSEC Conference.

[6] Weerheijm, J. and Van Doormaal,
J.C.A.M. 2007. Tensile failure of concrete at high loading rates: New test data on strength and fracture energy from instrumented spalling tests. Int. Journal of Impact Engineering 34: 609-626.

[7] Weerheijm et all. 2013. Understanding the tensile properties of concrete. Ed. by Weerheijm, J., Woodhead Publishing Lmt.

[8] Wittmann, F.H. 1977. Grundlagen eines Models zur Beschreibung charakteristischer Eigenschaften des Betons. Deutscher Ausschuss fur Stahlbeton, Vol. 290, 45. 